\title{
ANALISA PENGARUH PENERAPAN MANAJEMEN KUALITAS DENGAN MBNQA KRITERIA TERHADAP KINERJA BISNIS PADA RUMAH SAKIT ISLAM JEMURSARI SURABAYA
}

\author{
Arief Sabda Pietra Mukti Sutikno \\ Febriana Wurjaningrum \\ Departemen Manajemen Fakultas Ekonomi dan Bisnis Universitas Airlangga
}

\begin{abstract}
Abstrac
Today, high population growth coupled with the needs of the product or service quality healthcare. One practice in improving quality is through the implementation of Total Quality Management or TQM. One of the efforts in the implementation of TQM can be done with criteria MBNQA consisting of leadership, strategic planning, customer focus, pekuruan, analysis, and knowledge management, workforce focus, process management, and business results. RSI Jemursari Surabaya as one of the hospitals of foundation hospitals islam Islam Surabaya (Yarsis) has implemented MBNQA in its business operations. This study examines the relationship between TQM implementation through MBNQA on business performance criteria of Islamic Hospital Jemursari. Data were analyzed using path analysis using Partial Least Square method with the help of software SmartPLS. From the research results obtained by the t-statistic for the criteria of customer focus 6.153 ; management process by $5.451 ; 5.168$ leadership; strategic planning 4.314; and 2,628 business results. While the measurement, analysis, and knowledge management did not prove significant influence and adversely affect the value of the path coefficient of -0.014 with $0.288 t$ and the focus of labor is not proved significant with path coefficient value of 0,020 with 0,349 t.
\end{abstract}

Keywords: Quality, Performance, TQM, MBNQA, RSI Jemursari Surabaya.

\subsection{Pendahuluan}

\subsubsection{Latar Belakang}

Pada perkembangan penduduk saat ini sangatlah berpengaruh terhadap kebutuhan pelayanan, terutama pelayanan bidang kesehatan. Rumah Sakit Islaim Surabaya Jemursari. Rumah Sakit Islam Jemursari merupakan salah satu dari 3 instansi yang dikelola oleh Yayasan Rumah Sakit Islam Surabaya (YARSIS). Dua yang lainnya adalah Rumah Sakit Islam Surabaya Ahmad Yani dan Sekolah Tinggi Ilmu Kesehatan (STIKES) Yarsis. Rumah Sakit Islam yang terletak di jalan Jemursari ini merupakan tipe rumah sakit dengan tipe B. Dalam menjalankan bisnis RSI Jemursari telah mengimplementasikan TQM. Dalam pengembangan perbaikan manajemen 


\section{Arif Sabda Pietra Mukti Sutikno Febriana Wurjaningrum}

kulaitas layanan RSI Jemursari mulai menerpakan kriteia Malcom Baldrige. Ini merupakan upaya rumah sakit untuk meningkatkan kinerja bisnisnya, dan merupakan strategi rumah sakit untuk mencapai target rumah sakit yang bertaraf internasional, sesuai dengan visi dan misi RSI jemursari. Sebagai salah satu rumah sakit besar di Surabaya, Rumah Sakit Islam Jemursari berusaha meningkatkan kualitas layanan yang dimilikinya. Selain peningkatan jumlah layanan kesehatan, rumah sakit juga mendapatkan adanya peningkatan jumlah complain mengenai layanan yang diberikan. Complain yang terjadi di RSI Jemursari masih terus bertambah setiap tahunnya sesuai dengan bertambah jumlah pasien yang berobat di RSI Jemursari, baik di bagian pelayanan seluruh poli, pelayanan rawat inap, maupun pelayan pasien BPJS. Dengan adanya permasalahan tersebut, maka RSI Jemursari perlu adanya pemeriksaan atau evaluasi ulang terhadap manajemen mutu yang diterapkan oleh Rumah Sakit Islam Jemursari. Melalui evaluasi maka rumah sakit akan mengetahui secara jelas mengenai kondisi organisiasi dan pengimplementasian dari sistem manajemen kualitas terhadap keseluruhan kinerja organisasi, yang nantinya digunakan sebagai acuan untuk peningkatan produktivitas dan kinerja rumah sakit kearah yang lebih baik.

\subsubsection{Rumusan Masalah}

Berdasarkan uraian latar belakang masalah diatas, maka didapat rumusan masalah, yaitu:

1. Apakah sistem manajemen kualitas dengan MBNQA kriteria kepemimpinan memiliki pengaruh terhadap kinerja bisnis RSI Jemursari Surabaya?

2. Apakah sistem manajemen kualitas dengan MBNQA kriteria perencanaan strategi memiliki pengaruh terhadap kinerja bisnis RSI Jemursari Surabaya?

3. Apakah sistem manajemen kualitas dengan MBNQA kriteria fokus pelanggan memiliki pengaruh terhadap kinerja bisnis RSI Jemursari Surabaya?

4. Apakah sistem manajemen kualitas dengan MBNQA kriteria analisis dan informasi memiliki pengaruh terhadap kinerja bisnis RSI Jemursari Surabaya?

5. Apakah sistem manajemen kualitas dengan MBNQA kriteria fokUs SDM memiliki pengaruh terhadap kinerja bisnis RSI Jemursari Surabaya?

6. Apakah sistem manajemen kualitas dengan MBNQA kriteria manajemen proses memiliki pengaruh terhadap kinerja bisnis RSI Jemursari Surabaya?

7. Apakah sistem manajemen kualitas dengan MBNQA kriteria hasil bisnis memiliki pengaruh terhadap kinerja bisnis RSI Jemursari Surabaya?

8. Variabel kriteria MBNQA apa saja yang memiliki pengaruh signifikan terhadap kinerja bisnis pada Rumah Sakit Islam Jemursari Surabaya? 


\section{Jurnal Manajemen Teori dan Terapan \\ Tahun 8. No. 1, April 2015}

\subsubsection{Tujuan Penelitian}

Sejalan dengan rumusan masalah diatas maka tujuan dari penelitan ini adalah sebagai berikut :

1. Untuk menganalisis pengaruh antara penerapan manajemen kualitas dengan kriteria MBNQA terhadap kinerja bisnis Rumah Sakit Islam Jemursari Surabaya.

2. Untuk mendapatkan variabel yang berpengaruh dominan dari sistem manajemen kualitas dengan kriteria MBNQA terhadap kinerja bisnis pada Rumah Sakit Islam Jemursari.

\subsection{Landasan Teori}

\subsubsection{Konsep Pengukuran Kinerja}

Menurut Nanni et al dalam Suwignnjo, 2011 proses pengukuran kinerja ini pada dasarnya akan mencatat perkembangan sebagai dasar tindakan untuk memonitor dan mempertahankan kontrol pada suatu organisasi, dimana prosesnya adalah memastikan organisasi menjalankan strategi yang sesuai dengan visi dan misinya.

\subsubsection{Kinerja Bisnis}

Menurut Hult et al dalam IGN Widya 2013 Kinerja bisnis didefinisikan sebagai tujuan yang dicapai organisasi yang dihubungkan dengan profitabilitas dan pertumbuhan penjualan dan pangsa pasar, seperti pencapaian umum strategi objektif perusahaan

Menurut Benito et al dalam Naraswati (2011) kinerja bisnis dibagi kedalam empat tipe pengukuran kinerja, yaitu:

1. Profitabilitas/kinerja ekonomis perusahaan,yang terdiri atas laba, margin, ROI.

2. Respon pasar, merupakan reaksi terhadap permintaan pasar, dimana terdiri atas penjualan, pertumbuhan penjualan, dan pangsa pasar.

3. Nilai posisi pasar, yang didefinisikan sebagai pencapaian dan posisi menguntungkan dalam pemikiran konsumen, terdiri atas kepuasan konsumen, reputasi, loyalitas konsumen, dan image.

4. Kesuksesan produk baru.

\subsubsection{TQM dan Kinerja}

Menurut Demirbag et al (dalam Munizu, 2010) yang melakukan studi empiris unruk mengidentifikasi faktor-faktor penting bagi keberhasilan TQM pada UKM di Turki. Mereka menyimpulkan bahwa ada tujuh critical success factors (CSF) praktik TQM, yaitu data dan pelaporan kualitas, peran manajemen puncak, hubungan karyawan, manajemen kualitas pemasok, pelatihan, kebijaksanaan mutu dan manajemen proses 


\section{Arif Sabda Pietra Mukti Sutikno Febriana Wurjaningrum}

Menurut Prayogo dan Hong (dalam Munizu, 2010) melakukan penelitian pada 130 industri Manufaktur unit R\&D di Korea. Hasil penelitiannya menemukan bahwa implementasi praktik TQM yang semakin efektif mempunyai pengaruh signifikan terhadap kinerja perusahaan.

\subsubsection{Total Kualitas Manejemen}

\subsubsection{Teori Kualitas}

Menurut Phillip B. Crosby kualitas adalah conformance to requirement. Produk atau jasa memiliki kualitas atau mutu yang baik apabila sesuai dengan standar atau kriteria mutu yang telah di tentukan

Juran mendefinisikan kualitas dengan cukup sederhana. Kualitas menurut pemahaman beliau adalah "kesesuaian untuk digunakan". Hal ini mencakup tentang keistimewaan produk yang memenuhi kebutuhan konsumen dan bebas dari definisi.

\subsubsection{Konsep Total Quality Management (TQM)}

Menurut Krajewski dan Ritzman dalam Munizu, 2010. Total Quality Management (TQM) merupakan paradigma baru dalam menjalankan bisnis yang berupaya memaksimumkan daya saing organisasi melalui fokus pada kepuasan konsumen, keterlibatan seluruh karyawan, dan perbaikan secara berkesinambungan atas kualitas produk, jasa, manusia, proses dan lingkungan organisasi.

Menurut Besterfield et al (Kotturshettar et al, 2012), TQM didefinisikan sebagai seni dalam mengelola keseluruhan organisasi untuk mencapai keunggulan. Secara umum, TQM dapat diartikan sebagai aplikasi dari berbagai metode kuantitatif dan kualitatif (tools dan teknik) dan kegiatan sumberdaya manusia (prinsip-prinsip dan praktik)

\subsubsection{Implementasi TQM melalui Quality Award: MBNQA}

Prinsip-prinsip TQM telah banyak dijumpai dalam literatur, tetapi dalam praktiknya setiap perusahaan dapat berbeda antara satu dengan yang lain. Umumnya perusahaan mengikuti model standar yang telah diketahui dan diterima oleh banyak perusahaan sebagai pedoman untuk melakukan praktik manajemen kualitas. Contohnya prinsip-prinsip TQM yang diwujudkan dalam praktik bisnis dan digunakan sebagai standar evaluasi praktik kualitas dalam perusahaan adalah kinerja Malcom Bridge National Quality Award (MBNQA), Singaporen Quality Award (SQA), Japan Quality Award (JQA) dan Deming Prize (DP). Dalam penelitian ini, yang menjadi pokok bahasan yaitu mengenai implementasi dari penerapan MBNQA untuk manajemen kualitas layanan dan kinerj bisnis dalam organisasi .kesehatan. 


\section{Jurnal Manajemen Teori dan Terapan Tahun 8. No. 1, April 2015}

The Malcolm Baldrige National Quality Award Assesment (MBNQA) merupakan penghargaan perstisius terhadap industri-industri nasional yang ada di Amerika Serikat pada upaya perusahaan untuk mnecapai perbaikan mutu secara terus menerus (Pun et al, 1999).

MBNQA diajukan untuk peningkatan kinerja perusahaan, membantu memberikan arahan, menyiapkan perencanaan secara menyeluruh, menilai kemajuan yang mengarah ke perusahaan kelas dunia, mengetahui bidang-bidang yang perlu diperbaiki, menentukan kekuatan yang sudah dimiliki dan perolehan award.

Didalam proses penyusunan dan aplikasi sistem manajemen kualitas, kriteria baldrige ini memiliki tujuan utama yaitu sebagai berikut :

1. Untuk membantu organisasi dalam mempraktekkan peningkatan kinerja, kemampuan dan hasil.

2. Untuk memfasilitasi komunikasi dan berbagi informasi praktik terbaik diantara perusahaan.

3. Untuk menyediakan alat kerja dalam memahami dan mengelola kinerja, panduan perencanaan, dan menciptakan kesempatan untuk pembelajaran organisasi (McGuire, 2007).

Di dalam MBNQA terdapat core values and concepts yang menjadi acara penerapannya, yang diwujudkan kedalam 7 kategori atau kriteria. Kriteria tersebut antara lain

1) Kepemimpinan dimaksudkan pada era pemimpin senior dalam menunjukkan nilai dan harapan kinerja yang terfokus pada konsumen dan stakeholder, pemberdayaan, inovasi, pembelajaran, dan arahan organisasi.

2) Perencanaan strategis, yang dimaksudkan untuk mengetahui proses pengembangan strategi organisasi, yang mencakup cara peningkatan kelincahan organisasi dalam mengetasi perubahan lingkungan.

3) Fokus pelanggan, kategori ini dimaksudkan tentang cara organisasi menetapkan tujuan untuk mendengarkan tuntutan, harapan, dan kecenderungan konsumen dan keterlibatan pelanggann.

4) Pengukuran, Analisis, dan Manajemen Pengetahuan, hal ini dimaksudkan sebagai sistem pengukura kinerja organisasi, termasuk suara pelanggan, dan cara organisasi menganalisi kinerja diseluruh level dan seluruh bagian dalam organisasi.

5) Fokus Tenaga Kerja dimaksudkan tentang sebagai cara organisasi yang memungkinkan karyawan mengembangkan dan menggunakan sebagai potensi mereka untuk disesuaikan dengan tujuan organisasi mengupayakan organisasi untuk mengembangkan dan memperbaiki lingkungan kerja dan mendukung iklim yang 
Arif Sabda Pietra Mukti Sutikno

Febriana Wurjaningrum

kondusif kinerja yang sedang baik, partisipasi yang penuh pertumbuhan organisasi. Kategori yang meliputi lingkungan tenaga kerja dan keterlibatan tenaga kerja.

6) Management proses, kategori ini dimaksudkan sebagai aspek kunci untuk management proses organisasi termasuk desain yang terfokus pada sisrem kerja dan proses kerja

7) Hasil bisnis, dimaksudkan sebagai identifikasi kinerja organisasi dan meningkatkan bisnis kunci, kepuasan pelanggan, kinerja financial, hasil SDM, kinerja organisasional, dll. ..

Namun upaya penerapan sistem manajemen kualitas dan TQM melakukan kriteria MBNQA ini, ada beberapa kendala yang sering dihadapi oleh perusahaan, kendala yang sering muncul diantaranya adalah waktu penyusunan, takut akan penilaian, kurangnya penilaian yang mumpuni, kurangnya pengakuan, sikap tidak mau berubah dan juga kurangnya komitmen.

Adapun framework dari Malcom Baldrige yang telah dijelaskan seperti penjelasan di atas yang dapat dilihat dari gambar berikut:

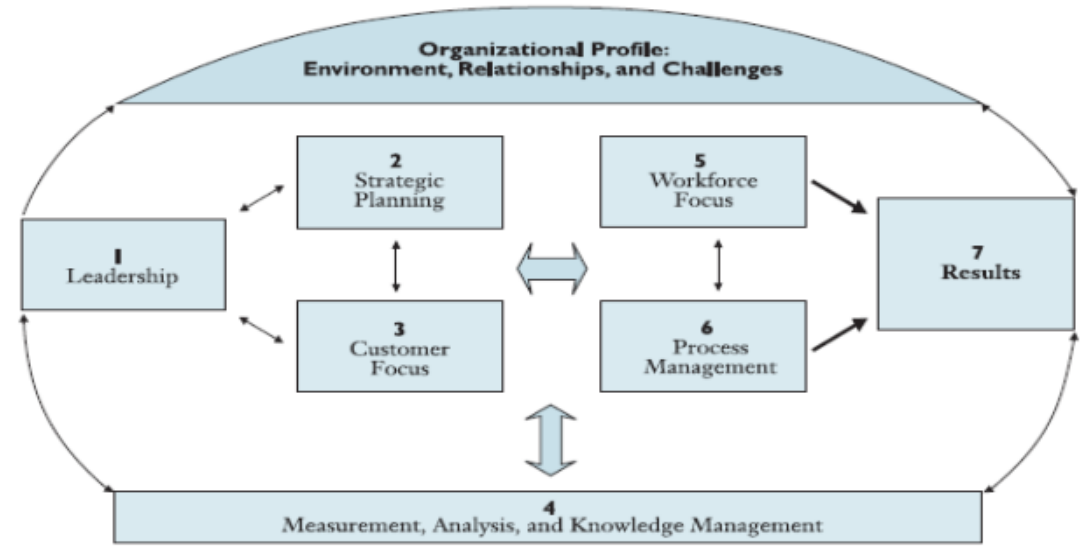

Sumber: (Sunil C. D'Souza dan A. H. Seqeuira, 2011:122)

\section{Gambar 1.1 MBNQA framework}

\subsection{Metode Penelitian}

\subsubsection{Pendekatan Penelitian}

Pada penelitian ini dilakukan dengan menggunakan pendekatan penelitian kuantitatif. Metode penelitian kuantitatif digunakan dengan tujuan agar proses penelitiannya dapat dilakukan secara tersetruktur dan menggunakan sampel dalam jumlah yang besar sehingga dapat memawikili populasi. Data yang digunakan harus dapat terukur dan dapat akan menghasilkan suatu kesimpulan yang dapat dipertanggung jawabkan dan dapat digeneralisasikan. Penelitian ini bersifat kasual karena akan meneliti pengaruh antar variabel. 


\section{Jurnal Manajemen Teori dan Terapan \\ Tahun 8. No. 1, April 2015}

\subsubsection{Identifikasi Variabel}

Berdasarkan rumusan masalah, variabel-variabel yang digunakan dalam penelitian ini adalah :

1. Variabel Bebas (Independent variable)

Variabel bebeas merupakan variabel yang didalam penelitian ini nilainya tidak tergantung atau terpengaruh pada variable lain. Variabel bebas dalam penelitian ini adalah kriteria $M B N Q A$, yang terdiri dari :

a) Kepemimpinan (KP) $X_{1}$

b) Perancanaan Strategis (PS) $X_{2}$

C) Fokus Pelanggan (FP) $X_{3}$

d) Pengukuran, Analisis, dan Manajemen Pengetahuan (PAM) $X_{4}$

e) Fokus Tenaga Kerja (FTK) $X_{5}$

f) Manejemen Proses (MP) $X_{6}$

g) Hasil Bisnis (HB) $X_{7}$

2. Variabel Terikat (Dependent variable)

Variabel terikat adalah variabel yang dipengaruhi oleh variabel lain. Variabel terikat. Dalam penelitian ini adalah (Y) kinerja bisnis Rumah Sakit Islam Jemursari Surabaya

\subsubsection{Jenis dan Sumber Data}

Sumber data dari sebuah penelitian ada dua jenis. Dalam penelitian ini sumber data yang digunakan antara lain :

1. Data Sekunder

Data sekunder adalah data yang diperoleh dari observasi langsung dengan menyebarkan kusioner pada obyek yang diteliti.

2. Data Primer

Data primer merupakan data yang diperoleh dari penjelasan atau keterangan dari pihak lain, seperti internal perusahaan, baik dalam bentuk data lisan maupun data tulisan. 
Arif Sabda Pietra Mukti Sutikno

Febriana Wurjaningrum

\subsubsection{Prosedur Pengumpulan Data}

Prosedur dan pengumpulan data dalam penelitian ini dilakukan sebagai berikut :

1. Studi pustaka, yaitu dengan mengumpulkan data dan informasi melalui artikel, bukubuku, dokumentasi yang dimiliki rumah sakit, literatur serta penelititan-penelitian sebelum yang terkait dengan penelitian ini.

2. Kuisioner, yaitu sebuah metode pengumpulan data dengan menggunakan daftar yang berisi pilihan dengan mencantumkan nilai skor tertentu yang menggambarkan kondisi responden, Daftar tersebut kemudian diberikan kepada responden dan di isi sesuai dengan keadaan responden tanpa campu tangan peneliti, kemudian hasil pengisian kuisioner tersebut akan diolah dengan metode statistik.

\subsubsection{Populasi dan Sampel}

\subsubsection{Populasi}

Populasi adalah kumpulan dari seluruh elemen atau individu-individu yang merupakan sumber informasi dalam suatu penelitian (Sumarsono,2004: 53). Populasi dibatasi sebagai jumlah penduduk atau individu yang paling sedikit mempunyai satu sifat yang sama. Populasi yang digunakan dalam penelitian ini adalah seluruh karyawan Rumah Sakit Islam Jemursari Surabaya.

\subsubsection{Sampel}

Sampel adalah kelompok yang lebih kecil yang dipilih sebagai contoh atau perwakilan dari populasi yang akan diukur (Reaves, 1992: 97). Sampel dalam penelitian ini menggunakan pendekatan non random sampling yang diambil secara purposive.

Kriteria sampel dalam penelitian ini adalah person in charge dari manajemen RSI Jemursari Surabaya. Yang dimaksud person in charge, yaitu:

a) Manajemen tingkat atas (10 orang).

b) Kepala instalasi (10 orang)

c) Kepala unit.(27 orang)

Penyebaran kuisioner dilakukan secara door to door kepada para sampel karena melalui teknik ini data yang didapat akan lebih valid.

\subsubsection{Teknik Analisis}

Teknik yang digunakan dalam menganalisa data adalah Path Analysis yang akan mempermudah dalam melihat hubungan kausalitas yang akan diuji. Hubungan antar konstruk akan diperlihatkan dan ditunjukkan melauli anak panah, diamana anak panah tersebut menunjukan hubungan kausal langsung antara satu konstruk dengan konstruk yang lainnya. 


\section{Jurnal Manajemen Teori dan Terapan \\ Tahun 8. No. 1, April 2015}

Adapun beberapa asumsi yang harus dipenuhi agar bisa menggunakan Path Analysis adalah sebagai berikut :

1) Variable berskala interval atau rasio

2) Hubungan antar variabel harus lincar dan aditif

3) Semua variable residu tidak mempunyai korelasi satu sama lain

4) Pola hubungan antar variabel adalah rekursif

Pengolahan hasil kuisioner yang telah diisi oleh responden akan diberi nilai seusai jawaban masing-masing responden kemudian diolah menggunakan bantuan software Partial Least Square (PLS), dimana dalam pendekatan ini bersifat distribution free (Ghozali, 2012).

\subsection{Hasil dan Pembahasan}

\subsubsection{Evaluasi Outer Model}

\subsubsection{Convergent validity}

Evaluasi pertama pada outer model adalah convergent validity. Convergent validity diukur dengan melihat nilai outer loading dari masing-masing indikator. Suatu indikator dikatakan memenuhi convergent validity jika memiliki nilai outer loading $\geq 0,500$. Berikut adalah nilai outer loading masing-masing indikator pada variabel penelitian:

Tabel 1.1 Outer Model

\begin{tabular}{|c|c|c|c|c|c|c|c|c|}
\hline & Kepemimpinan & $\begin{array}{c}\text { Perencanaan } \\
\text { Strategis }\end{array}$ & $\begin{array}{c}\text { Fokus } \\
\text { Pelanggan }\end{array}$ & $\begin{array}{l}\text { Pengukuran } \\
\text { Analisis dan } \\
\text { Manajemen } \\
\text { Pengetahuan }\end{array}$ & $\begin{array}{c}\text { Fokus } \\
\text { Tenaga } \\
\text { Kerja }\end{array}$ & $\begin{array}{c}\text { Manajemen } \\
\text { Proses }\end{array}$ & $\begin{array}{l}\text { Hasil } \\
\text { Bisnis }\end{array}$ & $\begin{array}{c}\text { Kinerja } \\
\text { Bisnis }\end{array}$ \\
\hline 1 & 0,613 & 0,853 & 0,653 & 0,889 & 0,79 & 0,551 & 0,67 & 0,659 \\
\hline 2 & 0,76 & 0,726 & 0,616 & 0,701 & 0,575 & 0,622 & 0,79 & 0,862 \\
\hline 3 & 0,698 & 0,806 & 0,736 & 0,822 & 0,624 & 0,67 & 0,685 & 0,827 \\
\hline 4 & 0,667 & 0,867 & 0,58 & 0,821 & 0,729 & 0,79 & 0,713 & 0,678 \\
\hline 5 & 0,717 & 0,694 & 0,51 & 0,853 & 0,749 & 0,722 & 0,808 & 0,66 \\
\hline 6 & 0,721 & 0,783 & 0,705 & 0,727 & 0,713 & 0,75 & 0,568 & \\
\hline 7 & 0,804 & 0,786 & 0,735 & 0,821 & 0,883 & 0,787 & & \\
\hline 8 & & & 0,749 & & 0,815 & 0,772 & & \\
\hline
\end{tabular}

Sumber : Data di olah

Dari hasil outer model yang disajikan diatas, seluruh indikator dari masing-masing variabel telah memenuhi convergent validity dikarenakan memiliki nilai outer loading $\geq 0,500$. 
Arif Sabda Pietra Mukti Sutikno

Febriana Wurjaningrum

\subsubsection{Evaluasi discriminant validity}

Evaluasi kedua pada outer model adalah discriminant validity Discriminant validity diukur dengan menggunakan cross loading. Suatu indikator dikatakan memenuhi discriminant validity jika nilai cross loading indikator terhadap variabelnya adalah yang terbesar dibandingkan terhadap variabel lainnya:

Tabel 1.2 Discriminant Validity

\begin{tabular}{|c|c|c|c|c|c|c|c|c|}
\hline & Kepemimpinan & $\begin{array}{c}\text { Perencanaan } \\
\text { Strategis }\end{array}$ & $\begin{array}{c}\text { Fokus } \\
\text { Pelanggan }\end{array}$ & \begin{tabular}{|c|} 
Pengukuran \\
Analisis dan \\
Manajemen \\
Pengetahuan
\end{tabular} & $\begin{array}{c}\text { Folus } \\
\text { Tenaga } \\
\text { Kerja }\end{array}$ & $\begin{array}{c}\text { Manajemen } \\
\text { Proses }\end{array}$ & Hasil & $\begin{array}{c}\text { Kinerja } \\
\text { Bisnis }\end{array}$ \\
\hline $\mathbf{X 1 . 1}$ & 0,613 & 0,008 & 0,184 & 0,06 & 0,102 & 0,222 & $-0,13$ & 0,216 \\
\hline $\mathrm{X} 1.2$ & 0,76 & 0,044 & 0,327 & 0,148 & 0,034 & 0,288 & $-0,03$ & 0,388 \\
\hline $\mathbf{X} 1.3$ & 0,698 & 0,144 & 0,319 & 0,205 & 0,187 & 0,363 & 0,013 & 0,386 \\
\hline X1.4 & 0,667 & 0,152 & 0,099 & 0,261 & 0,052 & 0,283 & $-0,061$ & 0,332 \\
\hline X1.5 & 0,717 & 0,082 & 0,28 & 0,037 & 0,021 & 0,229 & $-0,052$ & 0,373 \\
\hline X1.6 & 0,721 & $-0,002$ & 0,155 & 0,217 & 0,059 & 0,228 & $-0,125$ & 0,237 \\
\hline $\mathbf{X 1 . 7}$ & 0,804 & 0,09 & 0,344 & 0,423 & 0,061 & 0,433 & 0,16 & 0,52 \\
\hline X2.1 & 0,103 & 0,853 & 0,19 & 0,187 & 0,313 & 0,28 & $-0,024$ & 0,363 \\
\hline X2.2 & $-0,011$ & 0,726 & 0,247 & 0,187 & 0,377 & 0,313 & $-0,001$ & 0,264 \\
\hline $\mathbf{X} 2.3$ & 0,211 & 0,806 & 0,281 & 0,188 & 0,376 & 0,494 & 0,323 & 0,529 \\
\hline X2.4 & 0,007 & 0,867 & 0,174 & 0,097 & 0,374 & 0,296 & 0,075 & 0,421 \\
\hline X2.5 & 0,168 & 0,694 & 0,229 & 0,18 & 0,302 & 0,289 & $-0,071$ & 0,426 \\
\hline X2.6 & 0,071 & 0,783 & 0,142 & 0,191 & 0,42 & 0,217 & 0,016 & 0,378 \\
\hline X2.7 & 0,001 & 0,786 & 0,248 & 0,18 & 0,307 & 0,248 & 0,101 & 0,373 \\
\hline X3.1 & 0,279 & 0,28 & 0,653 & 0,267 & 0,194 & 0,423 & 0,252 & 0,549 \\
\hline X3.2 & 0,398 & 0,253 & 0,616 & 0,272 & 0,185 & 0,248 & $-0,046$ & 0,337 \\
\hline X3.3 & 0,316 & 0,156 & 0,736 & 0,396 & 0,281 & 0,466 & 0,063 & 0,391 \\
\hline X3.4 & $-0,037$ & 0,187 & 0,58 & 0,116 & 0,367 & 0,336 & 0,262 & 0,469 \\
\hline X3.5 & 0,275 & 0,203 & 0,51 & 0,217 & 0,189 & 0,16 & $-0,065$ & 0,319 \\
\hline X3.6 & 0,047 & 0,144 & 0,705 & 0,189 & 0,247 & 0,188 & 0,124 & 0,338 \\
\hline $\mathbf{X 3 . 7}$ & 0,189 & 0,087 & 0,735 & 0,139 & 0,122 & 0,224 & 0,009 & 0,432 \\
\hline X3.8 & 0,483 & 0,133 & 0,749 & 0,414 & 0,223 & 0,267 & $-0,114$ & 0,42 \\
\hline X4.1 & 0,24 & 0,165 & 0,304 & 0,889 & 0,131 & 0,297 & 0,111 & 0,246 \\
\hline $\mathrm{X} 4.2$ & 0,055 & 0,146 & 0,159 & 0,701 & 0,19 & 0,096 & 0,113 & 0,229 \\
\hline $\mathrm{X4.3}$ & 0,347 & 0,325 & 0,339 & 0,822 & 0,144 & 0,255 & $-0,042$ & 0,345 \\
\hline X4.4 & 0,252 & $-0,021$ & 0,24 & 0,821 & $-0,004$ & 0,21 & 0,054 & 0,189 \\
\hline $\mathrm{X} 4.5$ & 0,207 & 0,19 & 0,29 & 0,853 & 0,05 & 0,275 & 0,083 & 0,258 \\
\hline X4.6 & 0,215 & 0,119 & 0,248 & 0,727 & 0,232 & 0,244 & 0,07 & 0,261 \\
\hline $\mathbf{X 4 . 7}$ & 0,268 & 0,191 & 0,427 & 0,821 & 0,243 & 0,448 & 0,288 & 0,426 \\
\hline $\mathrm{X5.1}$ & 0,004 & 0,32 & 0,243 & $-0,008$ & 0,79 & 0,245 & 0,216 & 0,294 \\
\hline $\mathrm{X} 5.2$ & $-0,022$ & 0,189 & 0,263 & $-0,024$ & 0,575 & 0,062 & $-0,009$ & 0,144 \\
\hline $\mathrm{X5.3}$ & $-0,06$ & 0,214 & 0,298 & 0,187 & 0,624 & 0,111 & 0,285 & 0,284 \\
\hline $\mathrm{X5.4}$ & 0,237 & 0,299 & 0,453 & 0,34 & 0,729 & 0,363 & 0,088 & 0,359 \\
\hline $\mathrm{X5.5}$ & 0,063 & 0,25 & 0,134 & 0,208 & 0,749 & 0,268 & 0,144 & 0,201 \\
\hline $\mathrm{X5.6}$ & 0,076 & 0,37 & $-0,002$ & 0,17 & 0,713 & 0,21 & 0,219 & 0,204 \\
\hline$\times 5.7$ & 0,12 & 0,371 & 0,306 & 0,14 & 0,883 & 0,28 & 0,343 & 0,48 \\
\hline $\mathrm{X} 5.8$ & 0,07 & 0,552 & 0,209 & 0,064 & 0,815 & 0,3 & 0,01 & 0,343 \\
\hline X6.1 & 0,364 & 0,282 & 0,315 & 0,197 & 0,144 & 0,551 & 0,134 & 0,387 \\
\hline X6.2 & 0,068 & 0,338 & 0,121 & 0,252 & 0,336 & 0,622 & 0,14 & 0,306 \\
\hline X6.3 & 0,385 & 0,091 & 0,333 & 0,198 & 0,215 & 0,67 & $-0,009$ & 0,36 \\
\hline X6.4 & 0,311 & 0,315 & 0,357 & 0,262 & 0,259 & 0,79 & 0,239 & 0,457 \\
\hline X6.5 & 0,353 & 0,25 & 0,268 & 0,413 & 0,137 & 0,722 & 0,296 & 0,549 \\
\hline $\begin{array}{r}\text { X6.6 } \\
\text { X6.7 } \\
\end{array}$ & $\begin{array}{l}0,225 \\
0,371 \\
\end{array}$ & $\begin{array}{l}0,234 \\
0,374\end{array}$ & $\begin{array}{l}0,402 \\
0,406\end{array}$ & $\begin{array}{l}0,252 \\
0,249\end{array}$ & $\begin{array}{c}0,21 \\
0,314\end{array}$ & $\begin{array}{c}0,75 \\
0,787\end{array}$ & $\begin{array}{l}0,327 \\
0,305\end{array}$ & $\begin{array}{l}0,503 \\
0,614\end{array}$ \\
\hline X6.8 & 0,312 & 0,362 & 0,325 & 0,146 & 0,286 & 0,772 & 0,211 & 0,527 \\
\hline $\mathbf{X 7 . 1}$ & 0,085 & 0,121 & 0,285 & 0,054 & 0,16 & 0,206 & 0,67 & 0,386 \\
\hline $\mathrm{X} 7.2$ & $-0,114$ & 0,024 & 0,051 & 0,082 & 0,206 & 0,272 & 0,79 & 0,352 \\
\hline $\mathbf{X} 7.3$ & $-0,164$ & 0,106 & 0,016 & 0,218 & 0,034 & 0,096 & 0,685 & 0,195 \\
\hline X7.4 & 0,01 & 0,157 & $-0,094$ & 0,035 & 0,142 & 0,297 & 0,713 & 0,304 \\
\hline X7.5 & 0,048 & $-0,021$ & 0,086 & 0,149 & 0,254 & 0,222 & 0,808 & 0,401 \\
\hline X7.6 & $-0,329$ & 0,039 & $-0,195$ & 0,102 & $-0,06$ & 0,008 & 0,568 & $-0,009$ \\
\hline Y.1 & 0,434 & 0,369 & 0,391 & 0,321 & 0,218 & 0,507 & 0,114 & 0,659 \\
\hline Y.2 & 0,473 & 0,427 & 0,542 & 0,214 & 0,421 & 0,566 & 0,496 & 0,862 \\
\hline Y.3 & 0,405 & 0,338 & 0,561 & 0,15 & 0,423 & 0,497 & 0,387 & 0,827 \\
\hline Y.4 & 0,234 & 0,385 & 0,324 & 0,167 & 0,227 & 0,44 & 0,496 & 0,678 \\
\hline Y.5 & 0,372 & 0,403 & 0,508 & 0,58 & 0,246 & 0,482 & 0,184 & 0,66 \\
\hline
\end{tabular}


Sumber : Data di olah

Berdasarkan tabel diatas diketahui nilai cross loading semua indikator yang menyusun masing-masing variabel dalam penelitian ini (nilai yang dicetak tebal) telah memenuhi discriminant validity karena memiliki nilai cross loading terbesar untuk variabel yang dibentuknya dan tidak pada variabel yang lain. Dengan demikian semua indikator di tiap variabel dalam penelitian ini telah memenuhi discriminant validity.

\subsection{Akar AVE}

Metode lain yang dapat digunakan untuk mengetahui discriminant validity adalah dengan membandingkan nilai dari akar AVE tiap variabel dengan korelasi yang melibatkan variabel yang bersangkutan dengan variabel yang lainnya di dalam model. Jika nilai dari akar AVE lebih besar dibandingkan korelasi-korelasi yang terjadi maka variabel tersebut, maka dapat dikatakan variabel memenuhi discriminant validity.

Berikut adalah pengujian discriminant validity menggunakan perbandingan antara akar AVE dan korelasi antar variabel:

Tabel 1.3 Hasil Pengujian Discriminant Validity

\begin{tabular}{|l|c|c|c|c|c|c|c|c|c|c|}
\hline & AVE & $\begin{array}{c}\text { Average } \\
\text { Variance } \\
\text { Extracted } \\
\text { (AVE) }\end{array}$ & KP & PS & FP & PAM & FTK & MP & HB & KB \\
\hline KP & 0,510 & 0,714 & 1 & & & & & & & \\
\hline PS & 0,624 & 0,790 & 0,114 & 1 & & & & & & \\
\hline FP & 0,443 & 0,665 & 0,362 & 0,275 & 1 & & & & & \\
\hline PAM & 0,652 & 0,807 & 0,293 & 0,218 & 0,377 & 1 & & & & \\
\hline FTK & 0,549 & 0,741 & 0,100 & 0,446 & 0,343 & 0,191 & 1 & & & \\
\hline MP & 0,508 & 0,713 & 0,427 & 0,399 & 0,454 & 0,347 & 0,329 & 1 & & \\
\hline HB & 0,504 & 0,710 & - & 0,095 & 0,115 & 0,134 & 0,238 & 0,309 & 1 & \\
\hline KB & 0,551 & 0,743 & 0,519 & 0,515 & 0,633 & 0,370 & 0,426 & 0,671 & 0,4679 & 1 \\
\hline
\end{tabular}

Sumber: Data yang Diolah

Berdasarkan tabel diatas diketahui bahwa nilai akar AVE untuk setiap variabel adalah memiliki nilai lebih besar apabila dibandingkan dengan nilai korelasi antara variabel tersebut dengan variabel lainnya di dalam model, sehingga dapat disimpulkan bahwa variabel pada penelitian ini telah memiliki discriminant validity yang baik. 
Arif Sabda Pietra Mukti Sutikno

Febriana Wurjaningrum

\subsection{Composite reliability}

Evaluasi terakhir pada outer model adalah composite reliability. Composite reliability menguji kekonsistenan indikator-indikator dalam mengukur suatu konstruk.Suatu konstruk atau variabel dikatakan memenuhi composite reliability jika memiliki nilai composite reliability $\geq 0,700$

Berikut adalah nilai composite reliability masing-masing variabel:

Tabel 1.4. Composite Reliability

\begin{tabular}{|l|c|}
\hline & $\begin{array}{c}\text { Composite } \\
\text { Reliability }\end{array}$ \\
\hline Kepemimpinan & 0,878 \\
\hline Perencanaan Strategis & 0,920 \\
\hline Fokus Pelanggan & 0,862 \\
\hline $\begin{array}{l}\text { Pengukuran Analisis dan } \\
\text { Manajemen Pengetahuan }\end{array}$ & 0,929 \\
\hline Fokus Tenaga Kerja & 0,905 \\
\hline Manajemen Proses & 0,891 \\
\hline Hasil & 0,858 \\
\hline Kinerja Bisnis & 0,858 \\
\hline
\end{tabular}

Sumber: Data yang Diolah

Tabel diatas menunjukkan bahwa nilai composite reliability dari setiap variabel penelitian memiliki nilai lebih dari 0,700. Dengan demikian dapat disimpulkan bahwa masing-masing variabel telah memenuhi composite reliability.

\subsubsection{Evaluasi Inner Model}

\subsection{Nilai R-Square}

Evaluasi pertama pada inner model dilihat dari nilai R-Square atau koefisien determinasi. Berdasarkan pengolahan data dengan PLS, dihasilkan nilai R-Square sebagai berikut:

Tabel 1.5 Nilai $R$-Square

\begin{tabular}{|l|l|}
\hline Variabel & R-square \\
\hline Kinerja Bisnis & 0,791 \\
\hline
\end{tabular}

Sumber: Data yang Diolah 


\section{Jurnal Manajemen Teori dan Terapan \\ Tahun 8. No. 1, April 2015}

Dari tabel 1.5 diketahui Nilai R-Square untuk kinerja bisnis adalah sebesar 0,791 memiliki arti bahwa prosentase besarnya pengaruh kepemimpinan, perencanaan strategis, fokus pelanggan, pengukuran, fokus tenaga kerja, manajemen proses dan hasil bisnis terhadap kinerja bisnis adalah sebesar $79,1 \%$ sedangkan sisannya dijelaskan oleh variabel lain yang tidak diteliti. Berdasarkan hasil tersebut, model struktural pada penelitian telah memiliki goodness of fit yang baik.

\subsection{Pengujian Hipotesis}

Pengujian hipotesis penelitian dengan menggunakan analisis PLS dilakukan dengan menggunakan tabel inner weight. Hipotesis penelitian dapat diterima jika nilai $\dagger$ hitung (tstatistic) $\geq \dagger$ tabel pada tingkat kesalahan (a) $5 \%$ yaitu 1,96. Berikut adalah nilai koefisien path (original sample estimate) dan nilai thitung (t-statistic) pada inner model:

Tabel 1.6 Hasil Nilai Koefisien Path dan t-hitung

\begin{tabular}{|l|c|c|}
\hline \multicolumn{1}{|c|}{ Pengaruh } & Koefisien Path & T Hitung \\
\hline Kepemimpinan -> Kinerja Bisnis & 0,302 & 5,168 \\
\hline Perencanaan Strategis -> Kinerja Bisnis & 0,283 & 4,314 \\
\hline Fokus Pelanggan -> Kinerja Bisnis & 0,327 & 6,153 \\
\hline $\begin{array}{l}\text { Pengukuran Analisis dan Manajemen } \\
\text { Pengetahuan -> Kinerja Bisnis }\end{array}$ & $-0,014$ & 0,288 \\
\hline Fokus Tenaga Kerja -> Kinerja Bisnis & 0,020 & 0,349 \\
\hline Manajemen Proses -> Kinerja Bisnis & 0,352 & 5,451 \\
\hline Hasil Bisnis -> Kinerja Bisnis & 0,170 & 2,628 \\
\hline
\end{tabular}

Sumber: Data yang Diolah

Dari tabel diatas dapat disimpulkan bahwa, kriteria MBNQA yang terbukti berpengaruh positif dan signifikan terhadap kinerja bisnis Rumah Sakit Islam Jemursari Surabaya adalah fokus pelanggan, manajemen proses, kepemimpinan, perencanaan strategis, dan hasil bisnis. Untuk variabel pengukuran, analisis dan manajemen pengetahuan tidak terbukti signifikan dan berpengaruh negatif terhadap kinerja bisnis Rumah Sakit Islam Jemursari Surabaya dengan nilai koefisien path -0,014 dengan † hitung 0,288 yang lebih kecil dari † tabel. Sementara untuk variabel fokus tenaga kerja terbukti tidak signifkan dan berpengaruh positif terhadap kinerja bisnis dengan nilai koefesien path 0,020 dengan t hitung 0,349. 


\subsubsection{Saran}

1 Rumah sakit perlu mempertahankan capainnya dan melakukan peningkatan fokus pelanggan dengan memperbaiki tanggapan kritikan dan saran dari para konsumen, sehingga akan terjadi respon cepat tanggap yang berdampak pada kepuasan pelanggan dan loyalitas pelanggan sehingga RSI Jemursari Surabaya menjadi menjadi lebih unggul dari rumah sakit lainnya.

2 Perlunya peningkatan dan pemahaman terhadap data yang diterima disetiap masingmasing lini rumah sakit terhadap kebutuhan yang ada, kemudian diperlukan juga analisis kinerja internal dan eksternal rumah sakit, perlu adanya komunikasi yang lebih terbuka baik secara vertikal maupun horizontal, hal ini untuk memfasilitasi karyawan agar dapat mediskusikan permasalahan yang terjadi dilapangan dengan para manajer secara langsung maupun dengan sesama karyawan. Informasi pendidikan dan pelatihan sebaiknya di sebarkan dengan baik dan jelas dengan cara memberi informasi dengan layar tv Icd yang berisi khusus kegiatan internal (seminar, diklat, dan rapat) rumah sakit atau setiap manajer dan kepala unit menginformasikan secara rutin ke anggotanya.

Daftar Referensi

Baldrige National Quality Program (201 1), "201 1-2012 Criteria Performance Excellence", www.quality.nist.gov diakeses pada 17 Maret 2015 pkl.09.45.

D'Souza Sunil and Sequeira A.H. (2011). MBNQA - A Strategic Instrument for Measuring Performance in Healthcare Organizations : An Empirical Study, International Journal of Multidisciplinary Research, Vol.1 Issue 5, September 2011, ISSN 22315780.

D'Souza Sunil and Sequeira A.H. (2011). Application of MBNQA for service quality management and performance in healthcare organizations, International Journal of Engineering, Science and Technology Vol. 3, No. 7, 2011, pp. 73-88

Hadi, IGN Widya (2013), Analisa Pengaruh Implementasi Total Qualty Management Dengan Kriteria MBNQA Terhadap Kinerja Bisnis Pada PT PLN (PERSERO) Area Distribusi Bali Utara. Skripsi. Surabaya : Universitas Airlangga. 


\section{Jurnal Manajemen Teori dan Terapan Tahun 8. No. 1, April 2015}

Jonathan, Sarwono. 2006. "Metode Penelitian Kuantitatif dan Kualitatif".Yogyakarta: Graha IImu

Kiswanto. 2007. Implementasi Manajemen Kualitas dan Pengaruhnya pada Kinerja

Perusahaan Ditinjau dari sudut pandang Total Quality Management (Studi Empiris Terhadap Manager Perusahaan Manufaktur di Jawa Tengah). Tessis : Universitas Diponegoro.

Latan, Hengky. Ghozali, Imam, (2012), Partial Least Square (PLS) Konsep,Teknik dan Aplikasi SmartPLS 2.0 M3. Semaran 2012g : Badan Penerbit Universitas Diponegoro

Moses L. Singgih. "Penilaian kinerja suatu jurusan dengan kriteria Malcom Baldrige National Quality Award dan penentuan rangking menggunakan Analytical network Process"

Munizu, Musran. 2010. Praktik Total Quality Management (TQM) Dan Pengaruhnya Terhadap Kinerja Karyawan (Studi Pada PT. Telkom Tbk. Cabang Makasar). Jurnal Manajemen dan Kewirausahaan, Vol.12,No. 2, SEPTEMBER 2010: 185-194.

Sutikno, Arief Sabda Pietra Mukti dan Febriana Wurjaningrum, 2015. Analisa Pengaruh Penerapan Manajemen Kualitas Dengan MBNQA Kriteria Terhadap Kinerja Bisnis Pada Rumah Sakit Islam Jemur Sari Surabaya, Program Studi S1 Manajemen Fakultas Ekonomi dan Bisnis Universitas Airlangga, 141.

Tjiptono, Fandy. 2001. Total Quality Management. Yogyakarta: Penerbit ANDI.

http://rsisjs.com/ 